\title{
Impact of occupational stress on irritable bowel syndrome pathophysiology and potential management in active duty noncombat Greek military personnel: a multicenter prospective survey
}

\author{
Apostolis Papaefthymiou ${ }^{\mathrm{a}, \star}$, Michael Doulberis ${ }^{\mathrm{d}, \mathrm{g}, \star}$, Jannis Kountouras ${ }^{\mathrm{d}}$, Christina Kolokytha ${ }^{\mathrm{b}}$, \\ Michail Galanopoulos ${ }^{c}$, Christos Liatsos ${ }^{a}$, Nikolaos Kyriakos ${ }^{a}$, Marios Giakoumis ${ }^{a}$, Michail Papadomichelakis ${ }^{a}$, \\ Stergios A. Polyzos ${ }^{e}$, Georgios Kotronis ${ }^{\prime}$ and Panagiotis Katsinelos ${ }^{d}$
}

\begin{abstract}
Introduction Irritable bowel syndrome (IBS) is one of the gut-brain axis interaction disorders. It has global distribution with varying prevalence and particular financial and psychological consequences. IBS has been associated with stress and anxiety, conditions that are usually prevalent in the army. There are scarce data investigating the impact of IBS on noncombat active duty military without reports of Greek military or stress in the occupational environment.

Materials and methods The main exclusion criteria in our noncombat military multicenter prospective survey were gastrointestinal pathologies, malignancies, hematochezia, recent infections and antibiotics prescription, and pregnancy. Questionnaires included a synthesis of baseline information, lifestyle, and diet, psychological and stress-investigating scales and the IBS diagnosis checklist. Hospital Anxiety and Depression Scale and Rome IV criteria were utilized.

Results Among 1605 participants included finally, the prevalence of IBS was 8\% and 131 cases were identified. Women were more vulnerable to IBS, although male sex was prevalent at a ratio of 3.5:1 (male: female) in the entire sample. The mean age of all participants was 23.85 years; most of the IBS patients were older than thirty. Abnormal anxiety scores and high levels of occupational stress were related to an IBS diagnosis.

Discussion This prospective multicenter survey showed, for the first time, the potential impact of occupational stress on IBS in active duty noncombat Greek Military personnel. The diagnosis of IBS by questionnaire is a quick, affordable way that can upgrade, by its management, the quality of life and relieve from the military burden. Our results are comparable with previous studies, although large-scale epidemiological studies are required for the confirmation of a possible causative relationship. Eur $\mathrm{J}$ Gastroenterol Hepatol 31:954-963

Copyright () 2019 Wolters Kluwer Health, Inc. All rights reserved.
\end{abstract}

\section{Introduction}

Irritable bowel syndrome (IBS) is one of the most frequent functional gastrointestinal (GI) disorders in clinical practice, defined by the presence of chronic or recurrent abdominal pain associated with altered bowel habits

\footnotetext{
European Journal of Gastroenterology \& Hepatology 2019, 31:954-963

Keywords: Greek, gut-brain axis, irritable bowel syndrome, military, occupational stress

aDepartment of Gastroenterology, 401 General Military Hospital of Athens, bepartment of Mathematics, National and Kapodistrian University of Athens, 'Department of Gastroenterology, Evangelismos, Ophtalmiatreion Athinon and Polyclinic Hospitals, Athens, dDepartment of Internal Medicine, Second Medical Clinic, Ippokration Hospital, eFirst Department of Pharmacology, Medical School, Aristotle University of Thessaloniki, 'Department of Internal Medicine, Agios Pavlos General Hospital, Thessaloniki, Greece and 9Department of General Internal Medicine, University Hospital Inselspital Bern, Bern, Switzerland

Correspondence to Apostolis Papaefthymiou, MD, Department of Gastroenterology, 401 General Military Hospital of Athens, Athens 11525, Greece

Tel: + 4130210749 4500; e-mail: appapaef@hotmail.com

${ }^{*}$ Apostolis Papaefthymiou and Michael Doulberis contributed equally to the writing of this article.

Received 24 January 2019 Accepted 15 April 2019

Supplemental Digital Content is available for this article. Direct URL citations appear in the printed text and are provided in the HTML and PDF versions of this article on the journal's website, www.eurojgh.com.
}

(constipation, diarrhea, or both) [1,2]. The updated Rome IV criteria are widely considered the gold-standard symptom-based diagnostic tool [3]. Its prevalence in the general population worldwide is $12 \%$ [4]; similarly, its prevalence in Greece is also reported to be about $13-15 \%$ $[5,6]$.

IBS is considered one of the main forms of the so-called disorders of the gut-brain axis (G-BA) interaction [7], formerly also known as functional GI disorders [8-10]. Accumulating evidence has shown an interrelationship between the hypothalamic-pituitary-adrenal axis, gutassociated immune tissues, and the enteric nervous system under stress [11]. IBS appears to be a multifactorial disorder comprising visceral hypersensitivity, dysmotility of alimentary tract in the absence of any organic etiology, neuroendocrine dysfunction, psychological morbidity, genetics and epigenetics, dysbiosis, diet, and immune system activation [12]. Psychological concerns such as stress play an important role in the onset of IBS [13]. Specifically, its psychosocial and worldwide financial burden increases substantially as IBS ranks as one of the most common causes of admission to gastroenterology clinics as well as the most commonly diagnosed GI pathology [14].

IBS frequently overlaps with psychiatric disorders, most commonly with anxiety [14-19], depression [9,18-20], and 
post-traumatic stress [17,21,22]. In addition, occupational stress has been recognized as a major component of daily life. Stress is defined as 'a response of the organism to various stimuli, positive or negative, real or perceived' and occupational stress or stress at work is 'a result of an imbalance between demands and the ability to satisfy them' [23]. Moreover, postinfection IBS has been reported by epidemiology studies carried out in various geographic and clinical settings [24]. In this respect, IBS can be considered a 'stress disorder' [25] and has been studied from diverse perspectives at almost all levels of the gut-brain-microbiome axis [26]; altered fecal and mucosal microbial composition in patients with postinfection IBS correlates with psychological distress [27] and gut microbiota correlate with psychological and clinical characteristics in IBS, comprising stress, anxiety, and depression [26].

Specifically focusing on the military setting, the crucial impact of occupational stress on different army Corps [28-31] as well as in relevant occupations, such as security forces [32-34], is well documented. A recent review underlines the importance of nondeployment occupational stressors in the military environment, thereby strengthening the hypothesis that they could increase the risk of IBS [35]. Military personnel are occasionally affected by stressful environments, especially during combat training, and are frequently exposed to unfavorable conditions such as extreme weather or long-term separation from their families. Moreover, infectious diarrhea is relatively common among soldiers who have to move to different barracks or even travel to regions of the world with high travelers' diarrhea rates without rigorous hygiene regimes $[8,15,21,36,37]$.

Only limited epidemiological publications have studied the above-mentioned association among military personnel $[8-10,15,21,36-39]$, particularly on non-developed military forces. In Europe, armed forces of the UK represent the only population that has been studied during deployment to the Iraq war [21]. Importantly, none of the previously published relevant studies were based on the updated Rome IV criteria [40] to diagnose IBS. Besides, to our knowledge, a correlation between IBS and occupational stress in armed forces has never been evaluated before.

The aim of this prospective multicenter study was to investigate the potential impact mainly of occupational stress and other relative predisposing factors on IBS in active duty Greek noncombat military centers.

\section{Materials and methods}

\section{Study design - sample population}

This prospective multicenter survey was conducted from January to November 2017 after approval by the institutional review board for medical research of Greek armed forces (protocol number: 040/3/781590). The study was carried out in 15 military centers nationwide. Among these 15 centers, two were Military Academies, six were domains' Application Schools (infantry, armored, artillery, communications, sanitary, finances), one was a Military Hospital, five Units along the borders and, as 15th, the Hellenic Army General Staff.
The sample size initially consisted of 1800 participants, who were recruited to the Armed Forces at least 9 months ago. Participants were enrolled in this study after providing full informed consent. To achieve satisfactory statistical power and interpretability in our study sample, we calculated the least number of study participants needed using a well-established sample formula [41,42]; the minimum number was found to be 1156 participants who had completed a baseline survey. For the purposes of calculation, the already known median prevalence of $14 \%$ for Greek population $[5,6]$ was used to achieve an IBS prevalence precision of $\pm 2 \%$ with a $95 \%$ confidence interval. A response rate of $70 \%$ was postulated. All the participants participated voluntarily and were unidentifiable. Informative material was provided about the purpose of this survey, stating clearly that there were neither potential linked risks nor any penalty or loss of benefits if candidates chose not to participate in this research study or to withdraw (Supplementary File 1, Supplemental digital content 1, http://links.lww.com/EJGH/A412). The latter form served additionally as an obtained informed consent, given that the participants returned a fully completed anonymous questionnaire on a voluntary basis.

Exclusion criteria were incomplete answered questionnaires, which were a priori discarded. Specific questions clarified biases such as history of malignancy, hematochezia, or IBD; suspicion of rest organic GI pathology; acute infection that required treatment with antibiotics; and laxative abuse. Pregnant and females that whelped at least 36 weeks before, were excluded automatically from the study as they were out of duty. Moreover, significant psychiatric disorders such as schizophrenia had already been screened during the recruitment phase in the Greek army and all of these individuals were obviously excluded from the military personnel. It is noteworthy that according to the Greek military regulation, all soldiers are obliged to undergo annual clinical and laboratory evaluations. Therefore, this 'triaging' excluded major comorbidities and served as an additional filter, thereby having further enhanced the quality of our series by removing many potential cofounders. Finally, enlisted soldiers were not included because the time of service is too short in our country to evaluate the development of IBS.

All eligible questionnaires were coded and tabulated. The database was stored on a secure server that contained no personal identifiers. All of the variables, except for age and occupational stress score, were qualitative (categorical or ordinal). Periodic monitoring has been performed to review the data for completeness and adherence to protocol. Participants who did not complete the survey were also excluded. There was no attempted alternative means of contacting the participants other than those described below (e.g. distributing questionnaires per e-mail or post). There was also no reminder or second phase for military centers with low response rates.

\section{Data collection - questionnaire}

The essential data required for the study were collected by a self-report questionnaire (Supplementary File 2, Supplemental digital content 2, http://links.lww.com/EJGH/A413). The questionnaire was written originally in Modern Greek and consisted of four main parts: baseline information, 
lifestyle and diet questions, psychological and stress-related scale, occupational stress assessment, and IBS diagnosis. No descriptive-open questions were included. All questionnaires were distributed only once during occupational hours in each military center after obtaining special permission. The time required for completion was about 10-15 min.

The first part of the questionnaire included personal as well as sociodemographic information, such as age, sex, military rank-specialty, and marital status.

In the second part, smoking, the presence of chronic diseases, eating disorders, frequency of exercise as well as sleeping duration were investigated. According to the recommendations of the National Sleep Foundation [43] and the American Academy of Sleep Medicine [44], adults require 7-9 h of sleep (young adults verge on the upper limits) to maintain optimal health. As the population of this study included mostly younger participants, the cut-off value of sleep time was set to the median duration of $8 \mathrm{~h}$. Participants' nutritional status was also assessed using the most common adiposity index, BMI, as follows: normal $\left(<25 \mathrm{~kg} / \mathrm{m}^{2}\right)$, overweight $\left(25-30 \mathrm{~kg} / \mathrm{m}^{2}\right)$, and obese $\left(>30 \mathrm{~kg} / \mathrm{m}^{2}\right)$. In addition, a Food Frequency Questionnaire was introduced, in order the hebdomadal consumption of meat, dairy, vegetables/ legumes and alcohol to be estimated. Similarly, the method of food preparation was inquired.

To evaluate and detect possible occupational stress or anxiety indices, a further questionnaire composed of seven questions (Supplementary File 2, Supplemental digital content 2, http:/links.lww.com/EJGH/A413) was used. Questions were based on relevant data that evaluated the impact of occupational stress on similar study populations $[34,45,46]$ and the associated psychosocial parameters with the onset of IBS [35,47]. This original addition included questions on nondeployment stressors, such as the participant's military responsibilities, frequent assignments, financial emoluments, and other relevant conditions in a military environment. The grading of the answers was based on a Likert-type scale [48] ranging from 1 to 5, ranging from less to more important, respectively. The total score, on aggregation of individual answers' grading, ranged between 7 and 35 .

Furthermore, an uncomplicated and well-established method for screening depression and anxiety was used; the Hospital Anxiety and Depression Scale (HADS) [49] is a widely known self-reporting questionnaire composed of 14 questions on anxiety and depression. Depending on the overall score of each participant, it was classified as follows: normal (scoring 0-7), borderline abnormal (scoring 8-10, interpreted as borderline, doubtful case), or abnormal (scoring 11-21, interpreted as a definitive case) separately for anxiety and depression. The aforementioned cut-off score of at least 8 has been validated by many relative studies with a satisfactory sensitivity and specificity (averagely 0.8 ) for both anxiety and depression [49-53].

To establish the diagnosis of IBS, the new revised Rome IV criteria, the gold standard of symptom-based diagnosis, have been utilized (Table 1) $[40,54]$. The specificity and sensitivity of Rome IV criteria for IBS were evaluated to be 97.1 and $62.7 \%$, respectively [55]. A further classification of IBS included the following subtypes: IBS with predominant diarrhea, IBS with predominant constipation, irritable bowel syndrome with mixed bowel habits $\overline{\text { Table 1. Diagnostic criteria for irritable bowel syndrome on the basis of }}$ Rome foundation [54]

\section{Rome IV (Current, published in May 2016)}

Recurrent abdominal pain on average $\geq 1$ day/week in the last 3 months associated with two or more of the following criteria:

1. Related to defecation

2. Associated with a change in the frequency of stool

3. Associated with a change in the form (appearance) of stool

Criteria fulfillment for the last 3 months with symptom onset $\geq 6$ months before diagnosis

(IBS-M), and IBS unclassified [7,40,56], although these are no longer considered (since Rome IV) distinct disorders.

\section{Statistical analysis}

Data analysis was carried out using the statistical package for the social sciences software for Windows (SPSS statistics 25, PC version, IBM Corp., Armonk, New York, USA).

Descriptive statistics were calculated to delineate the baseline characteristics of our sample. Pearson's $\chi^{2}$-test or Fisher's exact tests were performed to check the correlation not only among the independent variables but also between the independent and the dependent variables. Logarithmic regression models were used to control the factors that may influence the results. Binary logistic regression analyses included several independent variables that have been proposed in the literature to affect IBS and occupational stress as a novel burdening factor. The Hosmer and Lemeshow test confirmed the goodness of fit of our model to the variables. Significance was set at $P$ value less than 0.05 (two-tailed).

\section{Results}

\section{Demographic, social, lifestyle, and military characteristics} of the Greek military population

Of the total of 1800 participants who were included initially, 137 refused to participate in this study. The remaining 1663 participants completed the questionnaires, thereby providing their consent to participation. The response rate was $\sim 92 \%$. Thirty-five participants were also excluded from the study because of incompletely answered questionnaires and 23 additional participants fulfilled the exclusion criteria. Therefore, finally, in total, 1605 valid questionnaires were processed by statistical analysis (Fig. 1).

Unsurprisingly, men were 3.5 times more than women (1253 men to 352 women) and the mean age was 23.86 years (ranging from 17 to 53 years old). The majority of participants had a normal body weight, with a BMI ranging from 19 to $36 \mathrm{~kg} / \mathrm{m}^{2}$. In terms of marital status, most of the participants were single $(84.7 \%$, $n=1360)$ and nine were divorced.

The majority of answered questionnaires were obtained from students of Military Academies $(59.2 \%, n=950)$, whereas only 36 participants were senior officers. Besides Military Academy students, the remaining categories included combatant-trained (in peacetime) soldiers and staff in Logistics. Most of Logistics members belonged to Sanitary, being $18.6 \%(n=298)$ of all participants and scientifically more qualified. The demographic, social, and 


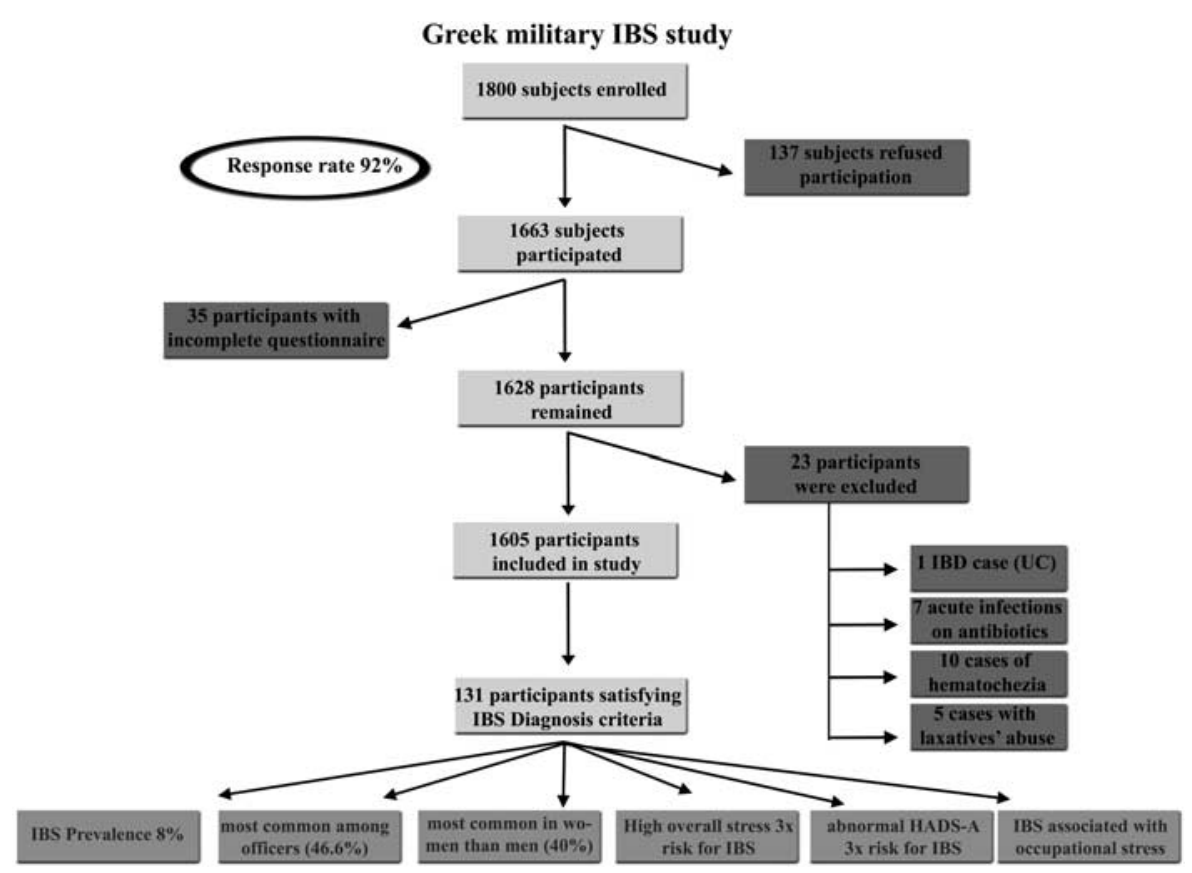

Fig. 1. Selection algorithm for the participants of the Greek IBS study along with the primary outcomes. HADS-A, hospital anxiety depression scale (anxiety variant); IBD, inflammatory bowel disease; IBS, irritable bowel syndrome; UC, ulcerative colitis.

military associated characteristics are summarized in Table 2.

Table 3 shows participants' lifestyle characteristics in detail. The majority of them $(92.2 \%, n=1480)$ did not have any chronic disease and the remaining participants presented with nondisabling comorbidities (e.g. hypothyroidism). In terms of the smoking habit, less than onethird currently smoked or had a history of smoking. Moreover, 90\% $(n=1484)$ of the participants exhibited physical exercise systematically, whereas only one-seventh of the enrolled staff certified a sleep duration more than $8 \mathrm{~h}$.

\section{Spectrum of irritable bowel syndrome in the Greek military population and correlation to the parameters studied}

Finally, 131 participants fulfilled the Rome IV diagnostic criteria for IBS. The calculated prevalence among individuals of Hellenic armed forces was $\sim 8 \%$. Interestingly, only seven of them consulted a gastroenterologist for their complaints. In terms of the four predefined IBS subtypes, the IBS-M type was the predominant one $(54.2 \%, n=71)$ (Fig. 2). In addition, more than one-fifth suffered from IBSdiarrhea type and only nine participants reported undefined symptoms.

IBS was found to be more common among Warrant Officers $(18.2 \%$ of them, $n=6)$. Sanitary soldiers were more susceptible than the soldiers of the rest of the army Corps, albeit without statistical significance. A hundred percent more women than men $(P=0.004)$ were found to suffer from IBS after using a model adjusting for many factors (Table 4). Participants between 30 and 39 years of age were significantly more susceptible to IBS $(P=0.041)$, whereas none of the soldiers older than 49 years of age suffered from IBS. Marital status did not affect the development of IBS.
Table 2. Demographic, social, and military associated characteristics

\begin{tabular}{|c|c|c|c|}
\hline Variables & Values & Frequency & Percentage \\
\hline \multicolumn{4}{|l|}{ Sex } \\
\hline & Male & 1253 & 78 \\
\hline & Female & 352 & 22 \\
\hline \multicolumn{4}{|l|}{ Age } \\
\hline & $<22$ & 850 & 53 \\
\hline & $22-29$ & 474 & 29.5 \\
\hline & $30-39$ & 205 & 12.8 \\
\hline & $40-49$ & 69 & 4.3 \\
\hline & $>50$ & 7 & 0.4 \\
\hline \multicolumn{4}{|l|}{ Specialty } \\
\hline & Combatant soldiers & 280 & 17.4 \\
\hline & Students & 950 & 59.2 \\
\hline & Logistics & 375 & 23.4 \\
\hline & Sanitary ${ }^{\mathrm{a}}$ & 298 & 18.6 \\
\hline \multicolumn{4}{|l|}{ Rank } \\
\hline & Students & 950 & 59.2 \\
\hline & Noncommissioned officers ${ }^{b}$ & 95 & 5.9 \\
\hline & Warrant officer & 33 & 2.1 \\
\hline & Lower officers $^{c}$ & 491 & 30.6 \\
\hline & Senior officers ${ }^{d}$ & 36 & 2.2 \\
\hline \multicolumn{4}{|l|}{ BMI } \\
\hline & Normal & 1173 & 73.1 \\
\hline & Overweight & 404 & 25.2 \\
\hline & Obese & 28 & 1.7 \\
\hline \multicolumn{4}{|c|}{ Marital status } \\
\hline & Married & 236 & 14.7 \\
\hline & Single & 1360 & 84.7 \\
\hline & Divorced & 9 & 0.5 \\
\hline
\end{tabular}

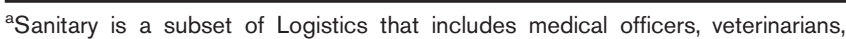
nurses, etc.

bNon-commissioned officers: 1. Master Sergeant; 2. Staff sergeant; 3. Sergeant; 4. Corporal; 5. Lance Corporal.

'Lower officers: 1. Captain; 2. First Lieutenant; 3. Second Lieutenant.

dSenior officers: 1. Colonel; 2. Lieutenant Colonel; 3. Major.

The lifestyle variables did not contribute significantly to the occurrence of IBS. Nevertheless, one of the Food Frequency Questionnaire-included food groups, vegetables and legumes, showed a negative association with IBS. This finding was statistically significant $(P=0.02)$. In contrast, 


\begin{tabular}{|c|c|c|c|}
\hline Variables & Values & Frequency & Percentage \\
\hline \multicolumn{4}{|c|}{ Chronic disease } \\
\hline & No & 1480 & 92.2 \\
\hline & Yes & 125 & 7.8 \\
\hline \multicolumn{4}{|l|}{ Smoking } \\
\hline & No & 1141 & 71.1 \\
\hline & Yes/previously & 464 & 28.9 \\
\hline \multicolumn{4}{|c|}{ Weekly alcohol consumption } \\
\hline & Never & 303 & 18.9 \\
\hline & $1-3$ days & 724 & 45.1 \\
\hline & 4-7 days & 578 & 36 \\
\hline \multicolumn{4}{|l|}{ Exercise } \\
\hline & Never & 131 & 8.2 \\
\hline & $1-3$ days & 668 & 41.6 \\
\hline & 4-7 days & 806 & 50.2 \\
\hline \multicolumn{4}{|c|}{ Sleep duration } \\
\hline & $<8 \mathrm{~h}$ & 1375 & 85.7 \\
\hline & $\geq 8 \mathrm{~h}$ & 230 & 14.3 \\
\hline
\end{tabular}

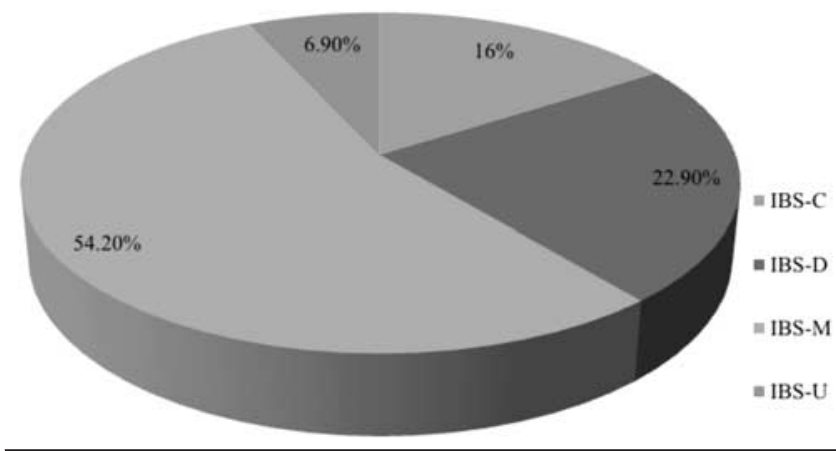

Fig. 2. IBS subtype frequencies calculated in percentages in the Greek Army. IBS-C, irritable bowel syndrome with predominant constipation; IBS-D, irritable bowel syndrome with predominant diarrhea; IBS-M: irritable bowel syndrome with mixed bowel habits; IBS-U, irritable bowel syndrome unclassified; IBS, irritable bowel syndrome.

participants who did not use to consume these victuals at least once a week were at risk for development of IBS. This likelihood was as high as $71 \%(P=0.024)$.

In the HADS questionnaire data, participants who were borderline abnormal (anxiety subtype) were 58\% more prone to develop IBS than the normal ones $(P=0.05)$. Moreover, participants with abnormal hospital anxiety depression scale anxiety variant levels showed almost 2.5 times higher risk for IBS occurrence, which was found to be highly statistically significant $(P=0.006)$. The results indicative for depression, however, were not found to be relative to IBS risk. The model used showed an association between G-BA interaction and overall occupational stress; for each unit of increase in the overall occupational stress scale score $($ minimum $=7)$, the relative possibility for IBS development increased by $5.6 \%(P=0.03$, Fig. 3$)$. The most substantial results of this study are shown in Fig. 4.

\section{Discussion}

Our prospective multicenter study investigated the potential impact of various parameters, including occupational stress, on IBS in active duty Greek noncombat military participants, using the Rome IV criteria [40] as the goldstandard diagnostic tool. Another innovation of our series was the investigated utilization of occupational stress as a key component for the onset of IBS in the mentioned peacetime, contrary to the majority of rest publications studied military populations, who were deployed at a combat field. Thus, we considered our participants to be a more representative sample, that reflected the mean army life in most western countries in peacetime, where daily occupational stress, rather than combat, dominated.

As expected, the Greek military population studied was characterized by a predominance of male participants, a result that is in accordance with other international studies of military populations $[9,10,21]$. In terms of the mean age and BMI of our sample, relevant publications reported similar results $[8,10]$, whereas the only UK study [21] did not report participants' mean BMI; a US military study [9] reported clearly older age and higher BMI values. Concerning subjects' military hierarchy, students of Military Academies, experiencing routine hard training, were enrolled in our survey. The rest, $40.2 \%$, of the participants were commissioned and noncommissioned officers, making our sample more balanced than in other studies $[8,9]$. In terms of the occupational specialty, soldiers in Logistics were slightly more than Combat staff; this gap was large in both USA and UK studies [9,21].

In addition, we found that only one-third of Greek military personnel included ex-smokers and current smokers, a proportion clearly lower than that in other relevant military studies $[9,21]$. Relative data indicate that smoking does not influence the prevalence of IBS [57].

Interestingly, about $90 \%$ of our participants exercised regularly and $92.2 \%$ of them were free of chronic diseases. In this respect, recent data indicate that a low-intensity to moderate-intensity exercise training program decreases the symptoms in IBS associated with a reversal of the ratio of anti-inflammatory to proinflammatory cytokines and facilitates blood redox homeostasis, thereby signifying an immune-modulating and redox-modulating function for exercise training [58]; augmented physical activity improves GI symptoms in IBS patients and physical activity could be introduced as a primary therapy modality in IBS [57]. However, only the minority of our participants experienced at least $8 \mathrm{~h}$ of sleep. In this respect, the prevalence of sleep disorders among IBS patients varies from 7.1 to $73.9 \%$ and sleep disturbances could be associated with more GI symptom severity [59]; individuals with adequate sleep are less likely to have IBS than individuals with sleep disturbance [57]. Therefore, the absence of adequate sleep observed in the majority our study population might explain, at least partly, the psychological distress symptoms in our participants.

There were no available data from IBS military studies of such parameters for direct comparison. However, the observed promising results of our study population could be easily explained by numerous factors: our population included rather young participants who were manifold and regularly controlled under the auspices of Hellenic armed forces for physical and mental disorders. Similarly, we hypothesized that the majority of them are self-motivated to follow a healthy lifestyle. Besides, the tactfully chosen exclusion criteria minimized the risk of cofounders. Remarkably, the absence of participants with pregnancy or malignancy could be attributed to the solicitousness of 
Table 4. Results of effects of sociodemographic, lifestyle, and psychosocial factors on irritable bowel syndrome among Greek military personnel

\begin{tabular}{|c|c|c|c|c|c|c|c|}
\hline \multirow[b]{2}{*}{ Variables } & \multirow[b]{2}{*}{ IBS [n (\%)] } & \multirow[b]{2}{*}{ No IBS [n (\%)] } & \multirow[b]{2}{*}{$\chi^{2}$} & \multirow[b]{2}{*}{$P$} & \multirow[b]{2}{*}{ OR } & \multicolumn{2}{|c|}{$95 \% \mathrm{Cl}$} \\
\hline & & & & & & Lower & Upper \\
\hline \multicolumn{8}{|l|}{ Sex } \\
\hline Female & $47(13.4)$ & 305 (86.6) & - & - & - & - & - \\
\hline Male & $84(6.7)$ & 1169 (93.3) & 10.06 & $0.002^{*}$ & 0.53 & 0.358 & 0.785 \\
\hline \multicolumn{8}{|l|}{ Age (years) } \\
\hline$<22$ & $59(6.9)$ & $791(93.1)$ & 1.318 & 0.251 & 0.765 & 0.485 & 1.208 \\
\hline $22-29$ & $37(7.8)$ & $437(92.2)$ & 10.643 & $0.031^{*}$ & & & \\
\hline $30-39$ & $26(12.7)$ & $179(87.3)$ & 4.16 & $0.041^{*}$ & 1.762 & 1.022 & 3.038 \\
\hline $40-49$ & $9(13)$ & $60(87)$ & 0.9 & 0.343 & 1.477 & 0.66 & 3.307 \\
\hline$>49$ & $0(0)$ & $7(100)$ & 0 & 0.999 & 0 & 0 & \\
\hline \multicolumn{8}{|l|}{ Specialty } \\
\hline Sanitary & $34(11.4)$ & $264(88.6)$ & 0.329 & 0.954 & - & - & - \\
\hline Combatant soldiers & $22(7.9)$ & $258(92.1)$ & 0.28 & 0.597 & 0.846 & 0.455 & 1.573 \\
\hline Students & $67(7.1)$ & $883(92.9)$ & 0.002 & 0.962 & 0.978 & 0.399 & 2.401 \\
\hline Logistics $^{a}$ & $8(10.4)$ & 69 (89.6) & 0 & 0.987 & 1.007 & 0.429 & 2.364 \\
\hline \multicolumn{8}{|l|}{ Rank } \\
\hline Students & $67(7.1)$ & $883(92.9)$ & 1.932 & 0.748 & - & - & - \\
\hline Noncommissioned officers & $10(10.5)$ & 85 (89.5) & 0.504 & 0.478 & 1.319 & 0.614 & 2.832 \\
\hline Warrant officer & $6(18.2)$ & $27(81.8)$ & 1.383 & 0.24 & 1.891 & 0.654 & 5.466 \\
\hline Lower officers & $44(9)$ & $447(91)$ & 0.033 & 0.855 & 1.047 & 0.64 & 1.714 \\
\hline Senior officers & $4(11.1)$ & 32 (88.9) & 0.001 & 0.97 & 0.976 & 0.284 & 3.353 \\
\hline \multicolumn{8}{|l|}{ BMI } \\
\hline Normal & $94(8)$ & $1079(92)$ & 0.52 & 0.771 & - & - & - \\
\hline Overweight & $33(8.2)$ & $371(91.8)$ & 0.223 & 0.647 & 0.902 & 0.587 & 7386 \\
\hline Obese & $4(14.3)$ & $24(85.7)$ & 0.214 & 0.643 & 1309 & 0,419 & 4094 \\
\hline \multicolumn{8}{|l|}{ Marital status } \\
\hline Married & $30(12.7)$ & 206 (87.3) & 2.064 & 0.356 & - & - & - \\
\hline Single & $100(7.4)$ & $1260(92.6)$ & 2.06 & 0.151 & 0.653 & 0.365 & 1.169 \\
\hline Divorced & $1(11.1)$ & $8(88.9)$ & 0.03 & 0.863 & 0.828 & 0.097 & 7.041 \\
\hline \multicolumn{8}{|l|}{ Smoking } \\
\hline No & $91(8)$ & $1050(92)$ & - & - & - & - & - \\
\hline Yes/previously & $40(8.6)$ & $424(91.4)$ & 0.002 & 0.962 & 1.01 & 0.671 & 1.52 \\
\hline \multicolumn{8}{|l|}{ Weekly alcohol consumption } \\
\hline Never & $25(8.3)$ & $278(91.7)$ & 0.226 & 0.893 & - & - & - \\
\hline $1-3$ days & $58(8)$ & $666(92)$ & 0.005 & 0.945 & 1.018 & 0.62 & 1.67 \\
\hline 4-7 days & $48(8.3)$ & $530(91.7)$ & 0.155 & 0.694 & 1.111 & 0.657 & 1.88 \\
\hline \multicolumn{8}{|l|}{ Weekly exercise } \\
\hline Never & $15(11.5)$ & $116(88.5)$ & 0.592 & 0.744 & - & - & - \\
\hline $1-3$ days & $60(9)$ & $608(91)$ & 0.073 & 0.787 & 0.916 & 0.486 & 1.726 \\
\hline 4-7 days & $56(6.9)$ & $750(93.1)$ & 0.419 & 0.517 & 0.791 & 0.388 & 1.61 \\
\hline \multicolumn{8}{|l|}{ Sleep duration (h) } \\
\hline$<8$ & $115(8.4)$ & $1260(91.6)$ & - & - & - & - & - \\
\hline$\geq 8$ & $16(7)$ & $214(93)$ & 0.875 & 0.35 & 0.769 & 0.443 & 1.334 \\
\hline Weekly vegetables/legumes c & & & & & & & \\
\hline Never & $5(20.8)$ & $19(79.2)$ & 5.417 & 0.067 & - & - & - \\
\hline 1-3 Weekly & $27(7.7)$ & 325 (92.3) & 4.864 & $0.027^{*}$ & 0.294 & 0.099 & 0.873 \\
\hline 4-7 Weekly & $99(8.1)$ & $1130(91.9)$ & 5.358 & $0.021^{*}$ & 0.292 & 0.103 & 0.828 \\
\hline HADS anxiety & & & & & & & \\
\hline Normal & $69(6.4)$ & $1016(93.6)$ & 8.255 & $0.016^{*}$ & - & - & - \\
\hline Borderline abnormal & $39(10.2)$ & $342(89.8)$ & 3.686 & $0.05^{\star}$ & 1.58 & 0.99 & 2.52 \\
\hline Abnormal & $23(16.5)$ & 116 (83.5) & 7.55 & $0.006^{*}$ & 2.41 & 1.287 & 4.514 \\
\hline HADS depression & & & & & & & \\
\hline Normal & $75(6.9)$ & 1010 & 1.602 & 0.449 & - & - & - \\
\hline Borderline abnormal & $42(10.8)$ & $348(89.2)$ & 1.541 & 0.214 & 1.337 & 0.845 & 2.114 \\
\hline Abnormal & $14(10.8)$ & $116(89.2)$ & 0.065 & 0.798 & 1.096 & 0.541 & 2.221 \\
\hline Occupational stress & - & - & 4.711 & $0.03^{*}$ & 1.056 & 1.005 & 1.109 \\
\hline
\end{tabular}

$\mathrm{Cl}$, confidence interval; HADS, Hospital Anxiety and Depression Scale.

'Logistics' soldiers other than sanitary staff.

${ }^{*} P \leq 0.05$ represents the variables values related statistical significantly with IBS after regression analysis.

Greek army to exclude such specific conditions from the active population.

It is important to note that the response rate of our questionnaire reached a satisfactory percentage of $92 \%$. This relatively high rate might be attributed to the great feeling of mutual collegiality and solidarity that characterizes Greek military personnel. Another plausible reason could be the participation of many aforementioned educated participants, who realized the importance and impact of such study.

The estimated prevalence of IBS in our Greek military survey was $8 \%$, a percentage considerably lower than the ones reported previously (13-15\%) by non-military Greek IBS data $[5,6]$. The discrepancy and variation were even greater $(4-33.5 \%)$ when the international prevalence of military IBS studies was taken into account $[8,39]$. This phenomenon could be interpreted on the basis of the following considerations: Rome IV diagnostic criteria were not used in the previously discussed studies and the elimination of the vague term 'abdominal discomfort' as well as the replacement of the word 'improvement' 'related' to defecation could potentially contribute to a more precise diagnosis. Moreover, genetic, cultural, geographical differences and the implication of another nature of military 
personnel among studies could pleotropically affect the prevalence of IBS (e.g. veterans who had actively fought in a war [39] vs. peacetime soldiers of our study population exercised regularly or different army Corps, for example, land army in our case versus aviation, where noise from airplanes was postulated to affect IBS development [8]). IBS is known to have a highly variable prevalence affected by many of the above-mentioned factors $[8,10,60]$.

An impressive outcome of our survey was that our soldiers did not seek a medical opinion on IBS symptoms. Only $5 \%(n=7)$ received an official IBS diagnosis after clinical examination. This observation was in line with our experience and reflected the soldiers' conception, which is characterized by increased durability and dedication to duty, thus inhibiting the evaluation of IBS effect on their performance.

Contrary to our previous publication [5] on the general Greek population, in this series, the most common subtype of IBS was the IBS-M type, with a percentage of $54.2 \%$.

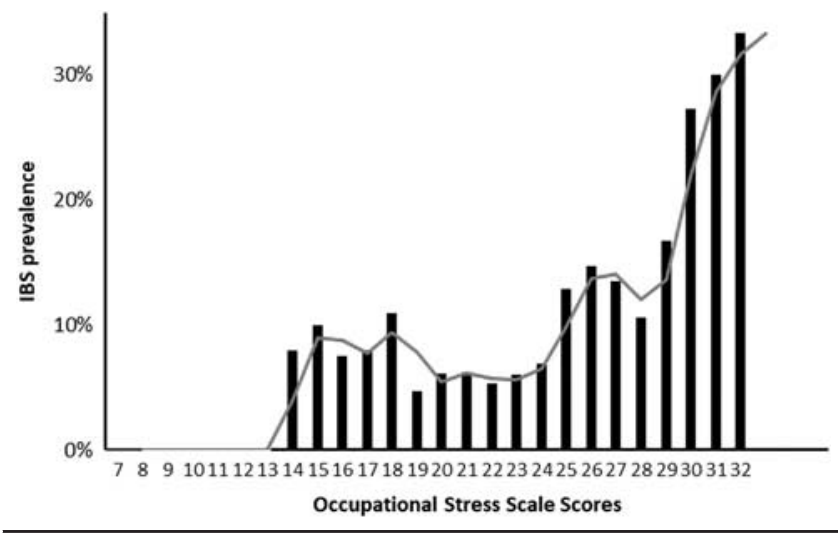

Fig. 3. IBS prevalence graph in association with occupational stress scale values. The grey line shows the tendency of IBS manifestation as the stress score increases. IBS, irritable bowel syndrome.
Data from other military-orientated IBS studies do not exist for direct comparison, whereas population-based studies from different countries [61-64] reported only contradictory results on the predominant subtype. This paradoxical at first glance phenomenon is in consistency with the Rome IV approach, where this classical subtyping lost its previous importance as the four known subtypes are no longer considered distinct disorders, but as a continuous spectrum of clinical features where the predominance of bowel habits during the time of disturbed bowel movement along with pain could be expressed variably in the same individual and may cause a switch or overlapping of subtypes with related changes in stool habit over time [40,54].

In terms of dietary factors and IBS, our findings indicated that avoidance of vegetables and legumes was associated with an increased risk for IBS development. Relevant information could not be retrieved from the existing military international IBS studies. Nevertheless, several IBS-related publications focusing on general population found opposite results [57,65-67].

By utilizing the HADS diagnostic tool for anxiety and depression, our data indicated a positive relationship only between both borderline abnormal and abnormal cases of anxiety type and IBS. Depression could not be correlated with the presence of IBS. Our results are in agreement with other IBS studies of army participants in terms of anxiety $[8,9,37,39]$. However, not all of the authors used a valid questionnaire such as HADS to quantify the anxiety. It is noteworthy that relevant studies on the general population confirmed our results, namely that only anxiety, but not depression, was associated with IBS $[68,69]$.

Occupational stress is an innovative parameter, which might contribute to the pathogenesis of IBS, albeit, to date, it had never been tested in the military population. Military environment is characterized by stressful conditions by a combination of parameters such as a strict

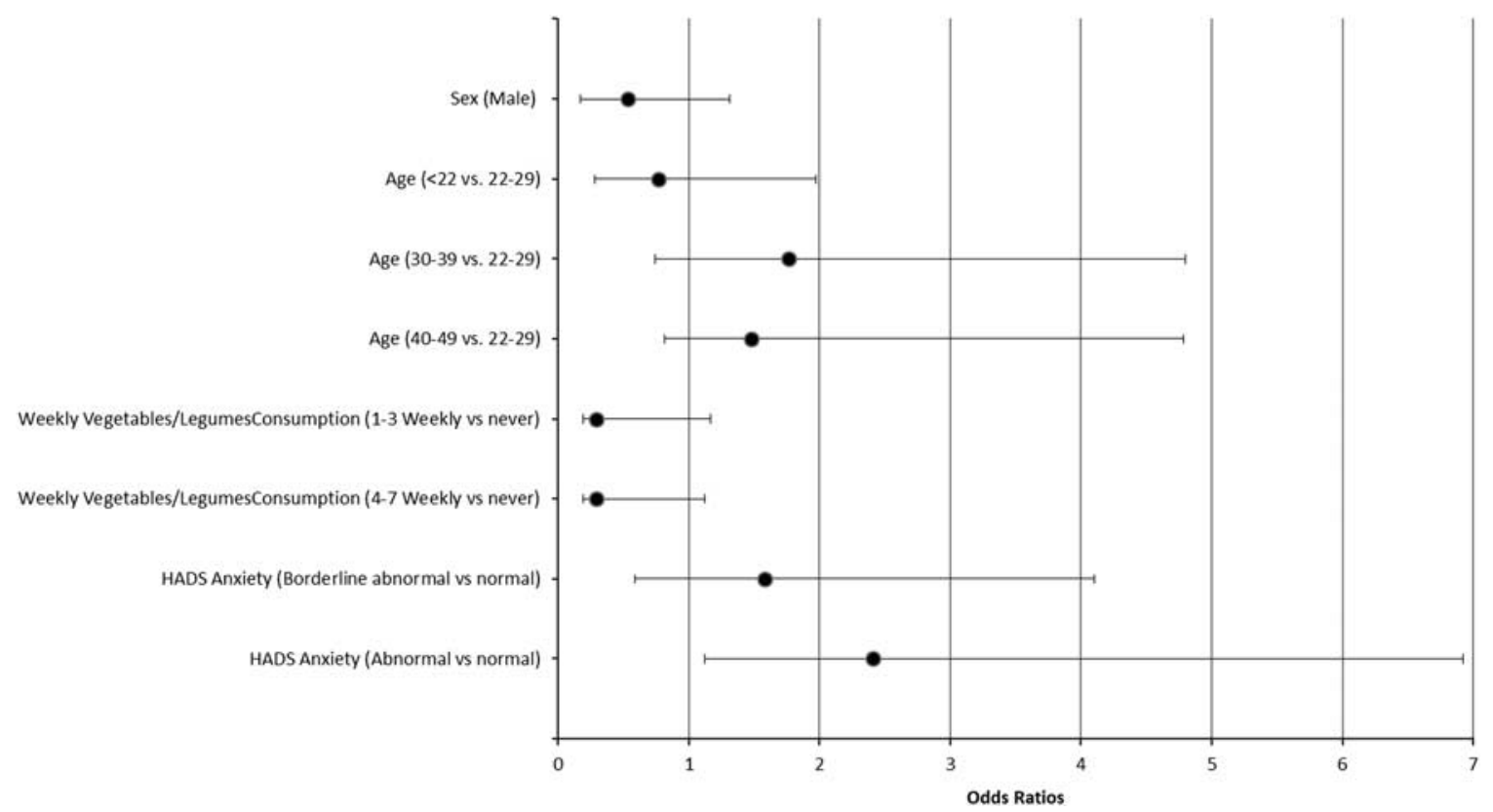

Fig. 4. Odds ratios and confidence intervals of variable values that affect significantly $(P \leq 0.05)$ IBS development in Greek Army. HADS, Hospital Anxiety and Depression Scale. 
hierarchy, unstable working schedule, residence instability, and hard physical and psychological training $[45,46]$. Financial, working and productivity burden of IBS has been established by several studies and could affect soldiers' performance during operations [21,70-72]. Our results showed a significant association between overall occupational stress and IBS. Increasing scores predisposed to a relatively higher occurrence of IBS for each added point to the stress scale [odds ratio (OR): 1.056, confidence interval: 1.005-1.109]. Despite the statistical significance, the low OR cannot prove an etiological relationship between occupational stress and IBS. This could be explained by the fact that we calculated the ORs considering occupational stress as a continuous variable instead of an arbitrary partition of cases into 'having' and 'not having' occupational stress. The very few studies that have investigated the impact of occupational stress on the occurrence of IBS in special populations were among firefighters of Korea [34] and a survey of nurses in the USA [73]. The first study, which included a total of 1217 participants, indicated that IBS-positive firefighters (diagnosed on the basis of Rome III criteria) showed statistically significant differences in occupational stress, generalized stress, self-esteem, and quality of life scores compared with the IBS negative ones. The latter study included 342 electronic questionnaires on occupational stress among nurses and ways to reduce it. Participants had an occupational stress median value equal to 4 (scale $0-5$ with increasing severity) and IBS was ranked as one of the most reported comorbidities.

Specifically, the model used in our series showed a linear association between G-BA interactions and overall occupational stress; a single unitary increased in occupational stress score multiplies the risk of IBS by $5.6 \%$ $(P=0.03)$. In this respect, the bi-directional G-BA interactions appear to be involved in IBS pathophysiology $[74,75]$. GI disorders including IBS are highly regulated by the brain and the G-BA seems to play an important role in the modulation of the GI immune system and mucosal inflammation; in this sense, mucosal mast cells at the cellular level and corticotropin-releasing factor at the molecular level appear to play an essential role [75].

The strengths of this study are summarized as follows: the study was population based and prospective, and had a cautiously made plan with statistical power and multiple parameters that enabled a reliable assessment of primary effects, controlling for multiple confounders and exploration of novel risk factors (primarily occupational stress). Moreover, a very limited number of relevant papers exist (especially using the new Rome IV diagnostic criteria). The inclusion of a very homogeneous population with national-racial consistency and the satisfactory sample of participants for the Greek dynamics could be admeasured to the positive components.

This series also had several limitations including the absence of a standardized, validated occupational stress scale adjusted for the active Greek military population. The latter led us to utilize customization - composition of questionnaires, which might have limited the objectivity of the results. Moreover, the classification of IBS subtypes, without the application of the Bristol stool scale, might be not very accurate, the last of which was not feasible because of the nature of survey. Furthermore, a limitation of the study is that there was no clinical examination or follow-up. In addition, as this was an epidemiological study, we cannot deduce conclusions regarding an isolated soldier, but can only describe population trends. Finally, it should be emphasized that the results of our series reflect a statistical association and do not suffice to prove a causal link between IBS and the parameters investigated.

\section{Conclusion}

The results of this study are generally consistent with the previous publications and support the hypothesis that IBS, as a main representative of G-BA interactions, is triggered by stressors and anxiety. Military personnel are clearly exposed to such conditions and occupational stress is a major factor associated with IBS. The global incidence of IBS inside and outside of the military environment is high, but a prompt diagnosis that requires a rather cost-effective method would have a major positive impact on future quality of life. Further large-scale epidemiological studies are warranted to elucidate the pathogenesis and the potential causative link.

\section{Acknowledgements}

The authors would like to dedicate this study to the memory of the victims of the recent Greek wildfire tragedy.

\section{Conflicts of interest}

There are no conflicts of interest.

\section{References}

1 Menees S, Chey W. The gut microbiome and irritable bowel syndrome. F1000Res 2018; 7:1029.

2 Zhang Y, Li Z, Han F. Electroacupuncture for patients with irritable bowel syndrome. Medicine (Baltimore) 2018; 97:e11627.

3 Mearin F, Lacy BE, Chang L, Chey WD, Lembo AJ, Simren M, et al. Bowel disorders. Gastroenterology 2016; 150:1393-1407.

4 Lovell RM, Ford AC. Global prevalence of and risk factors for irritable bowel syndrome: a meta-analysis. Clin Gastroenterol Hepatol 2012; 10:712-721.

5 Katsinelos P, Lazaraki G, Kountouras J, Paroutoglou G, Oikonomidou I, Mimidis K, et al. Prevalence, bowel habit subtypes and medical careseeking behaviour of patients with irritable bowel syndrome in Northern Greece. Eur J Gastroenterol Hepatol 2009; 21:183-189.

6 Viazis N, Papatheodoridis G, Vlachogiannakos J, Markoglou C, Vasianopoulou P, Vienna E, et al. T1822 prevalence of irritable bowel syndrome in the Greek General Population. Gastroenterology 2010; 138:S-586.

7 Schmulson MJ, Drossman DA. What is new in Rome IV. J Neurogastroenterol Motil 2017; 23:151-163.

8 Wu W, Guo X, Yang Y, Peng L, Mao G, Qurratulain H, et al. The prevalence of functional gastrointestinal disorders in the chinese air force population. Gastroenterol Res Pract 2013; 2013:1-6.

9 Riddle MS, Welsh M, Porter CK, Nieh C, Boyko EJ, Gackstetter G, et al. The Epidemiology of irritable bowel syndrome in the US military: findings from the Millennium Cohort Study. Am J Gastroenterol 2016; 111:93-104.

10 Carter D, Beer-Gabel M, Tzur D, Levy G, Derazne E, Novis B, et al. Predictive factors for the diagnosis of irritable bowel syndrome in a large cohort of 440,822 young adults. J Clin Gastroenterol 2015; 49:300-305.

11 Sugaya N, Izawa S, Saito K, Shirotsuki K, Nomura S, Shimada H. Effect of prolonged stress on the adrenal hormones of individuals with irritable bowel syndrome. Biopsychosoc Med 2015; 9:4.

12 Wu JC, Chan AOO, Chan YW, Cheung GCL, Cheung TK, Kwan AC, et al. The current treatment landscape of irritable bowel syndrome in 
adults in Hong Kong: Consensus statements. Hong Kong Med J 2017; 23:641-647.

13 Jang SH, Ryu HS, Choi SC, Lee SY. Psychological factors influence the irritable bowel syndrome and their effect on quality of life among firefighters in South Korea. Psychiatry Investig 2017; 14:434.

14 Soares RLS. Irritable bowel syndrome: a clinical review. World $J$ Gastroenterol 2014; 20:12144-12160.

15 Shelef L, Dotan S, Kaminsky D, Kedem R, Margulis A, Hassidim A. Relationship between anxiety and medical disorders among compulsory military service candidates between the years 1998-2013. Psychiatry Res 2016; 244:339-344.

16 Halpert A. Irritable bowel syndrome: patient-provider interaction and patient education. J Clin Med 2018; 7:3.

17 Ikechi R, Fischer B, DeSipio J, Phadtare S. Irritable bowel syndrome: clinical manifestations, dietary influences, and management. Healthcare 2017; 5:21.

18 Fond G, Loundou A, Hamdani N, Boukouaci W, Dargel A, Oliveira J, et al. Anxiety and depression comorbidities in irritable bowel syndrome (IBS): a systematic review and meta-analysis. Eur Arch Psychiatry Clin Neurosci 2014; 264:651-660

19 Banerjee A, Sarkhel S, Sarkar R, Dhali GK. Anxiety and depression in irritable bowel syndrome. Indian J Psychol Med 2017; 39:741-745.

20 Fournier A, Mondillon L, Dantzer C, Gauchez AS, Ducros V, Mathieu N, et al. Emotional overactivity in patients with irritable bowel syndrome. Neurogastroenterol Motil 2018; 30:e13387.

21 Goodwin L, Bourke JH, Forbes H, Hotopf M, Hull L, Jones N, et al. Irritable bowel syndrome in the UK military after deployment to Iraq: What are the risk factors? Soc Psychiatry Psychiatr Epidemiol 2013; 48:1755-1765.

22 Iorio N, Makipour K, Palit A, Friedenberg FK. Post-traumatic stress disorder is associated with irritable bowel syndrome in African Americans. J Neurogastroenterol Motil 2014; 20:523-530.

23 Trifunovic N, Jatic Z, DzuburKulenovic A. Identification of causes of the occupational stress for health providers at different levels of health care. Med Arch 2017; 71:169.

24 Barbara G, Grover M, Bercik P, Corsetti M, Ghoshal UC, Ohman L, et al. Rome foundation working team report on post-infection irritable bowel syndrome. Gastroenterology 2019; 156:46-58.

25 Mayer EA, Naliboff BD, Chang L, Coutinho SV. Stress and irritable bowel syndrome. Am J Physiol Gastrointest Liver Physiol 2001; 280: G519-G524.

26 Moser G, Fournier C, Peter J. Intestinal microbiome-gut-brain axis and irritable bowel syndrome. Wien Med Wochenschr 2018; 168:62-66.

27 Sundin J, Rangel I, Fuentes S, Heikamp-de Jong I, HultgrenHörnquist E, de Vos WM, et al. Altered faecal and mucosal microbial composition in post-infectious irritable bowel syndrome patients correlates with mucosal lymphocyte phenotypes and psychological distress. Aliment Pharmacol Ther 2015; 41:342-351.

28 Booth-Kewley S, Dell'Acqua RG, Thomsen CJ. Factors affecting organizational commitment in navy corpsmen. Mil Med 2017; 182: e1794800.

29 Schulze C, Becker M, Finze S, Holtherm C, Hinder J, Lison A. An evaluation of the significance of individual endogenous risk factors and medical and orthopaedic conditions on physical fitness in military executives. US Army Med Dep J 2017; 3:105-110.

30 Bravo AJ, Kelley ML, Hollis BF. Work stressors, sleep quality, and alcoholrelated problems across deployment: a parallel process latent growth modeling approach among Navy members. Stress Health 2017; 33:339-347.

31 Stacey MJ, Hill N, Woods D. Physiological monitoring for healthy military personnel. J R Army Med Corps 2018; 164:290-292.

32 Chudzicka-Czupała A, Stasiła-Sieradzka M, Dobrowolska M, Kułakowska A. Assessment of worklife areas and stress intensity among Border Guard officers. Med Pr 2018; 69:199-210.

33 Stanley IH, Boffa JW, Smith LJ, Tran JK, Schmidt NB, Joiner TE, et al. Occupational stress and suicidality among firefighters: examining the buffering role of distress tolerance. Psychiatry Res 2018; 266:90-96.

34 Choi SC, Jang SH, Ryu HS, Kim YS, Lee SY. Psychological factors influence the overlap syndrome in functional gastrointestinal disorders and their effect on quality of life among firefighters. Neurogastroenterol Motil 2016; 28:60.

35 Brooks SK, Greenberg N. Non-deployment factors affecting psychological wellbeing in military personnel: literature review. J Ment Health 2018; 27:80-90.

36 Porter CK, Gloor K, Cash BD, Riddle MS. Risk of functional gastrointestinal disorders in U.S. military following self-reported diarrhea and vomiting during deployment. Dig Dis Sci 2011; 56:3262-3269.
37 Li X, Kan EM, Lu J, Cao Y, Wong RK, Keshavarzian A, et al. Combattraining increases intestinal permeability, immune activation and gastrointestinal symptoms in soldiers. Aliment Pharmacol Ther 2013; 37:799-809.

38 Gutiérrez RL, Riddle MS, Porter CK. Increased risk of functional gastrointestinal sequelae after Clostridium difficile infection among Active Duty United States Military Personnel (1998-2010). Gastroenterology 2015; 149:1408-1414.

39 White DL, Savas LS, Daci K, Elserag R, Graham DP, Fitzgerald SJ, et al. Trauma history and risk of the irritable bowel syndrome in women veterans. Aliment Pharmacol Ther 2010; 32:551-561.

40 Drossman DA. Functional gastrointestinal disorders: history, pathophysiology, clinical features, and Rome IV. Gastroenterology 2016; 150:1262-1279e2.

41 Wang J. Clinical epidemiology, 2nd ed. Shanghai: Shanghai Science \&Technology Press; 2001

42 Taherdoost $\mathrm{H}$. Determining sample size; how to calculate survey sample size. Int J Econ Manag Syst 2017; 2:237-239.

43 Lichtenstein GR. The importance of sleep. Gastroenterol Hepatol (N Y) 2015; $11: 790$.

44 Watson NF, Badr MS, Belenky G, Bliwise DL, Buxton OM, Buysse D, et al. Recommended Amount of Sleep for a Healthy Adult: A Joint Consensus Statement of the American Academy of Sleep Medicine and Sleep Research Society. Sleep 2015; 38:843-844.

45 Kypraiou A, Sarafis P, Tsounis A, Bitsi G, Andreanides E, Constantinidis T, et al. Depression and anxiety in Greek male veterans after retirement. Mil Med 2017; 182:e163944.

46 Pflanz S, Sonnek S. Work stress in the military: prevalence, causes, and relationship to emotional health. Mil Med 2002; 167:877-882.

47 Surdea-Blaga T, Băban A, Dumitrascu DL. Psychosocial determinants of irritable bowel syndrome. World J Gastroenterol 2012; 18:616-626.

48 Sullivan GM, Artino AR. Analyzing and interpreting data from Likerttype scales. J Grad Med Educ 2013; 5:541-542.

49 Zigmond AS, Snaith RP. The Hospital Anxiety and Depression Scale. Acta Psychiatr Scand 1983; 67:361-370.

50 Stern AF. The Hospital Anxiety and Depression Scale. Occup Med (Chic III) 2014; 64:393-394

51 Olssøn I, Mykletun A, Dahl AA. The hospital anxiety and depression rating scale: a cross-sectional study of psychometrics and case finding abilities in general practice. BMC Psychiatry 2005; 5:46

52 Bocéréan C, Dupret E. A validation study of the Hospital Anxiety and Depression Scale (HADS) in a large sample of French employees. BMC Psychiatry 2014; 14:354.

53 Bjelland I, Dahl AA, Haug TT, Neckelmann D. The validity of the Hospital Anxiety and Depression Scale. An updated literature review. J Psychosom Res 2002; 52:69-77.

54 Lacy B, Patel N. Rome criteria and a diagnostic approach to irritable bowel syndrome. J Clin Med 2017; 6:99.

55 Palsson OS, Whitehead WE, van Tilburg MAL, Chang L, Chey W, Crowell MD, et al. Development and validation of the Rome IV diagnostic questionnaire for adults. Gastroenterology 2016; 150:1481-1491.

56 Simren M, Palsson OS, Whitehead WE. Update on Rome IV criteria for colorectal disorders: implications for clinical practice. Curr Gastroenterol Rep 2017; 19:15.

57 Guo YB, Zhuang KM, Kuang L, Zhan Q, Wang XF, Liu SD. Association between diet and lifestyle habits and irritable bowel syndrome: a case-control study. Gut Liver 2015; 9:649-656.

58 Hajizadeh Maleki B, Tartibian B, Mooren FC, FitzGerald LZ, Krüger K, Chehrazi $\mathrm{M}$, et al. Low-to-moderate intensity aerobic exercise training modulates irritable bowel syndrome through antioxidative and inflammatory mechanisms in women: results of a randomized controlled trial. Cytokine 2018; 102:18-25.

59 Wang B, Duan R, Duan L. Prevalence of sleep disorder in irritable bowel syndrome: a systematic review with meta-analysis. Saudi J Gastroenterol 2018; 24:141.

60 Chey WD, Kurlander J, Eswaran S. Irritable bowel syndrome: a clinical review. JAMA 2015; 313:949-958.

61 Zhang F, Xiang W, Li CY, Li SC. Economic burden of irritable bowel syndrome in China. World J Gastroenterol 2016; 22:10450-10460.

62 Adeniyi OF, Adenike Lesi O, Olatona FA, Esezobor Cl, Ikobah JM. Irritable bowel syndrome in adolescents in Lagos. Pan Afr Med J 2017; 28:93.

63 Cañón M, Ruiz AJ, Rondón M, Alvarado J. Prevalence of irritable bowel syndrome and health-related quality of life in adults aged 18 to 30 years in a Colombian University: an electronic survey. Ann Gastroenterol 2017; 30:67-75 
64 Saha M, Parveen I, Uddoula MS, Alam MJ, Afsar NS, Debnath BC, et al. Irritable bowel syndrome: prevalence and dietary factors in the Sylhet District of Bangladesh. Mymensingh Med J 2018; 27:82-88.

65 Hayes P, Corish C, O'Mahony E, Quigley EMM. A dietary survey of patients with irritable bowel syndrome. J Hum Nutr Diet 2014; 27 (Suppl 2):36-47.

66 Miwa H. Life style in persons with functional gastrointestinal disorders large-scale internet survey of lifestyle in Japan. Neurogastroenterol Motil 2012; 24:464-471.

67 Chirila I, Petrariu FD, Ciortescu I, Mihai C, Drug VL. Diet and irritable bowel syndrome. J Gastrointestin Liver Dis 2012; 21:357-362.

68 Lee S, Wu J, Ma YL, Tsang A, Guo WJ, Sung J. Irritable bowel syndrome is strongly associated with generalized anxiety disorder: a community study. Aliment Pharmacol Ther 2009; 30:643-651.

69 Hu WHC, Wong WM, Lam CLK, Lam KF, Hui WM, Lai KC, et al. Anxiety but not depression determines health care-seeking behaviour in Chinese patients with dyspepsia and irritable bowel syndrome: a population-based study. Aliment Pharmacol Ther 2002; 16:2081-2088.
70 Cash B, Sullivan S, Barghout V. Total costs of IBS: employer and managed care perspective. Am J Manag Care 2005; 11:S7-S16.

71 Buono JL, Carson RT, Flores NM. Health-related quality of life, work productivity, and indirect costs among patients with irritable bowel syndrome with diarrhea. Health Qual Life Outcomes 2017; 15:35.

72 Maguen S, Madden E, Cohen B, Bertenthal D, Seal K. Association of mental health problems with gastrointestinal disorders in Iraq and Afghanistan veterans. Depress Anxiety 2014; 31:160-165.

73 Kemper K, Bulla S, Krueger D, Ott MJ, McCool JA, Gardiner P. Nurses' experiences, expectations, and preferences for mind-body practices to reduce stress. BMC Complement Altern Med 2011; 11:26.

74 Quigley E. The gut-brain axis and the microbiome: clues to pathophysiology and opportunities for novel management strategies in irritable bowel syndrome (IBS). J Clin Med 2018; 7:6.

75 Kountouras J, Polyzos SA, Deretzi G. Multiple bidirectionality brain-gut interactions in patients with inflammatory bowel disease. Gastroenterology 2018; 155:1651-1652. 